\title{
Effect of Midwifery Students' Negative Clinical Experiences on Their Emotional Labor Behaviors
}

\author{
Fadime Bayri Bingol (D), Meltem Demirgoz Bal (D), Merve Aygun (D), Edanur Bilgic (D) \\ Marmara University, Health Sciences Faculty, Midwifery Department, Istanbul, Turkey.
}

Correspondence Author: Fadime Bayri Bingo

E-mail: fadimebayri@gmail.com

Received: $24.01 .2020 \quad$ Accepted: 14.10 .2020

\begin{abstract}
Objectives: Emotional labor is the effort type that organizations expect from their employees or the effort that the individual makes based on his/her mood. Negative clinical experiences in the workplace may have long-term influence on emotional labor behavior. Aim of this study was carried out to determine the effect of midwifery students' negative experiences in clinical practices on their emotional labor behaviors.

Methods: The study is a mixed-methods study. Thematic analysis and descriptive was used. The study was conducted from November to December 2018 with 370 midwifery students in Istanbul. The relevant data were collected via a "Descriptive Information Form" and Emotional Labor Behavior Scale of Nurses (ELBS).

Results: The mean age of the students recruited for the research is $21.57 \pm 1.51$. Eighty-five percent of students ( $n=314$ ) were identified to have at least one negative clinical experience, which decreased their motivations to be a midwife. "Healthcare professional's behaviors towards pregnant women during childbirth" rank first (48.1\%) among these negative experiences. A little more than the half of the students (51\%) react to these negative experiences by "staying away from the setting." It was identified that ELBS total score mean of students were $96.52 \pm 11.92$ and also that as students' fear to vaginal birth management increased, their ELBS scores decreased $(p=0,00, r=-0,22)$. It is determined that clinical negative experiences do not affect students' emotional labor behavior ( $p>0,05)$.

Conclusion: The factor affecting a large part of students' motivation to be midwife negatively is the healthcare professional's negative behaviors towards pregnant women and students. Within this context, it must be attempted to make healthcare personnel behave in a more humanistic and professional way towards women and students. Therefore, midwifery education programs should be planned and written about the qualifications that students should be knowledgeable and equipped to understand the emotional needs of women.
\end{abstract}

Keywords: Student midwives, clinical negative experience, emotional labor behavior.

\section{INTRODUCTION}

The "emotion", a feeling special to that one individual, is reflected on the person who takes the service from the employees. One of the most important concepts about healthcare quality in the field is the emotional labor, which means the effort to have the relevant facial and physical appearance and presence of the service-giver $(1,2)$. The employee has to manage her/his emotions to show the desired behavior during the service process $(3,4)$. The servicegiver needs to suppress some of his/her emotions and evoke some others just to make the service-taker feel comfortable, provide relevant social norms and reflect the emotions expected from him/her $(5,6)$. The concept of emotional labor was first used by Arlie Hochschild in 1983 (4). The concept of emotional labor is increasingly being discussed (1-4).

Throughout the literature, emotional labor concept is grouped under three different dimensions as superficial behavior, deep behavior and sincere behaviors. Superficial behavior occurs when the employee pretends to feel what he/she does not feel the way expected from him/her at that very moment $(1,2)$. Individuals show some positive emotions to the service-taker through controlling their momentary negative emotions and hide their own authentic emotions $(3,4)$. Deep behavior comes when the employee not only behaves like he/she feels the way expected or desired from her/him but also internalizes and handle that emotion $(5,7)$. Sincere behaviors means that what the individual feels corresponds to what he/she shows. Shortly, the individual does not make an extra effort to direct his/her emotions while behaving in an sincere behaviors way $(6,7)$. Midwives/ midwifery students offer one-to-one care containing emotional labor to women during their childbirth, the most important event for many women. 
Midwifery requires constant one-to-one communication, which affects emotional labor. Therefore, midwifery students need to handle their own emotions in birth clinics. Especially, in the intrapartum period, when women undergo an emotional and physical change, midwives have an active role. For an intrapartum period to end in a healthy way, midwives/midwifery students have to handle both their own and the woman's emotions. The midwives who cannot handle their own emotions in a good way may exhibit negative behaviors (8-10). This affects the quality of the care offered by midwives and midwifery students negatively and also may result in stress, decrease in motivation, intention to quit the job and burnout (11).

In this context, this study was planned to be conducted descriptively to identify the relationship between negative clinical experiences of senior midwifery students and their emotional labor behaviors and affecting factors.

\section{METHODS}

2.1. Research type: The study is a mixed-methods study. Thematic analysis and descriptive was used. In this this study consists of the senior midwifery students in the universities of Istanbul who accepted to participate in this study in between November-December 2018. No sample was selected and all students who accepted to participate in this study were recruited for this research. After the approval of the ethics committee, separate permission was obtained from each university. Appointments were made for students of each university to fill out the questionnaires outside the class hours. The researchers went to universities at specified appointment times. The researchers invited students to research by giving information about the research in the classroom. Students were provided to fill out questionnaires on a voluntary basis. A total of 465 students in senior grade of their undergraduate midwifery students were present in Istanbul on that date. Four hundred five volunteer students (88\%) joined and filled the questionnaires but missing forms were excluded and the research was completed with 370 students (80\%).

2.2. Data collection tools: The data were collected via Descriptive Information Form and Emotional Labor Behavior Scale for Nurses.

2.3. Descriptive Information Form: The General Information Form is based on examples in the literature and comprises queries on the participants' socio-demographic features (age, education, etc.) and clinical experiences of participants. Besides, students' fear to vaginal birth management was assessed using Visual Analog Scale (VAS). In this VAS assessment, participants were asked to mark the density of their fear emotions on a vertical line of 10 centimeter and then the marked point was measured with the help of a ruler. In this VAS assessment, childbirth fear scoring was as such: "I have no fear to vaginal birth management: 0 point" and "I am so afraid vaginal birth management: 10 points." The content of vaginal birth management fear was asked in an open-ended way. And the most negative experience that students underwent in the clinical setting, which decreased their motivations to be midwives, was asked in an openended way, either.

2.4. Emotional Labor Behavior Scale for Nurses (ELBS): Developed by Degirmenci-Oz and Baykal (2018), this scale consists of 24 items being 5-point Likert scale type. Responses to the expressions in the scale were graded as such: "I absolutely do not agree-1 point", "I do not agree-2 points", "I am indecisive-3 points", "I agree-4 points" and "I totally agree-5 points". The scale consists of 3 subscale including "Superficial behavior subscale" (Items from 1 to 6), "Deep behavior subscale" (Items from 7 to 19) and "Sincere behavior subscale (Items from 20 to 24). Deep behavior is that employees should be able to really feel the emotion that they need to reflect at that moment by organizing their emotions and behave accordingly. Superficial behavior is that employees simply change their behavior and act as though they do not actually feel that way. However, sincere behaviors comes when the employees act spontaneously and the way how he/she genuinely feels. When the scores from the scale are assessed, total score from each sub-scale is divided into item number in this sub-scale and the arithmetical mean is taken. As per this calculation, sub-scale score mean in each sub-scale varies between " 1 " and " 5 ". As the mean score in sub-scale comes close to " 1 ", emotional labor behavior decreases and as it comes close to " 5 ", the very same behavior increases (12). In this study, Cronbach alpha value of Emotional Labor Behavior was determined as .90 .

2.5. Data collection: After obtaining written permission from universities, data were collected in senior students' classes on their appropriate days and hours. These students were invited to participate in the study and asked to fill the forms on a voluntary basis.

2.6. Ethics of the study: A relevant approval was obtained from Marmara University Health Sciences Faculty NonInvasive Ethics Committee $\left(19^{\text {th }}\right.$ October 2018,30$)$ to conduct this study. Afterwards, written permission was obtained from 3 state and 6 foundation universities with midwifery bachelor programs in Istanbul with the approval of ethics committee to be able to carry out this study.

2.7. Analysis of data: Statistical analyses of the data were conducted using PSAS Statistics 21.0. After assessing individual traits of the students, mean \pm standard deviation, number and percent distributions were found. While comparing individual traits and ELBS scores, Student t test was used. $p<0,05$ was accepted as the statistical significance value. Students' expressions for negative clinical experiences were written on text document and then deciphered. Inductive qualitative content analysis was used to create themes in the analysis of students' clinical negative experiences (13). With this analysis method, both the apparent content obtained from the expressions of the participants and the content underlying the verbal expressions were analyzed with the interpretation of the researcher. The content of the text formed by students' answers were open-coded (determination of the expressions with similar meanings) and after specified expressions were 
named, they were coded. It is composed of three themes named in the meaning of the code.

\section{RESULTS}

It was determined that age mean of the students that were recruited was $21.57 \pm 1.51$ and $97.3 \%$ of them $(n=360)$ were single, $50.5 \%$ of them $(n=187)$ lived with their families and $76.8 \%$ of them $(n=284)$ were attending to a state university. It was also established that $11.6 \%$ of midwifery students $(n=43)$ did not want to work as midwives after graduation. It was determined that $28.9 \%(n=107)$ of the students had at least one traumatic experience and $17.6 \%(n=65)$ of them experienced violence at least once. It was found that $20 \%$ ( $n=74$ ) of the students included in the study perceived the delivery room as a dangerous place. And it was also detected that a great portion of the recruited students $(84.9 \%, n=314)$ had at least one negative clinical experience, which decreased their motivations to be midwives. Three main themes were identified when negative experiences that caused decrease in the motivations of midwifery students to work as midwives in a clinical setting were evaluated.

\section{Three main themes and the codes that make up the themes are as follows;}

1-Negative attitudes of healthcare professional towardspregnant women during childbirth (48.1\%, $n=178): 1.1$. Unprofessional approaches of obstetricians and midwives to pregnant women (physical or verbal violence against pregnant women during childbirth, ill-treatment, rude behaviors, non-emphatic attitudes and desensitization), 1.2.Failure to provide adequate care to pregnant women (none of the methods for coping with the pain are performed, absence of appropriate clinical setting in the hospital), 1.3.Unnecessary routine interventions (unnecessary episiotomy, induction without indications, constant Nonstress Test and movement restriction, restriction of nourishment and oral fluid intake during the labor, rush during the childbirth, episiotomy without anesthesia and its repair, detachment of mother and the child immediately after the childbirth), 1.4.Giving no information about the practices and no explanations about the risks and benefits of the waiting attempt, 1.5.Giving no importance to privacy, 1.6.Leaving the women alone often during the childbirth.

2-Negative attitudes of healthcare personnel towards students (21.9\%, $n=81$ ): 2.1. Insults, despises and overlooking behaviors of obstetricians and midwives against students, 2.2.Unsupportive and non-educatory attitudes of midwives, no permission for a student who follows a pregnant to manage that woman's childbirth, no permission for any practice and no answers to students' questions, 2.3.Non-compatibility between theory and practice, 2.4.Tasks in some other clinicals than gynecology clinics, 2.5.Unsupportive attitudes of school teachers in the clinical setting, inadequate clinical training.

3-Reasons stemming from childbirth room and its setting (14.9\%, $n=55)$ : 3.1.The rush of the childbirth room,
3.2.Dystocia, 3.3.Complications during the childbirth, 3.4.Babies with anomalies, 3.5.Mother and child deaths.

It was determined that the most frequent reaction of the students after the negative experience of the students during in clinics was to move away from clinical setting (50.8\%, n=188) (Table 1). ELBS total score mean of students was determined to be $96.52 \pm 11.92$ ( $\min : 52$, max:120) while their item score mean (total score/item number) was found to be $4,02 \pm 0,49$ (Table-2). It was found that ELBS scores of the students unsatisfied with midwifery education were significantly lower $(p<0,05)($ Table-3). It was also determined that ELBS score mean was not affected by negative experience, type of experience or the kind of reaction $(p>0,05)$ (Table-4). Additionally, it was determined that fear to vaginal birth management of the students corresponded to "the fear of hurting mother and the baby" and ELBS scores decreased $(p=0,000, r=-0,22)$ as the fear of childbirth increased.

Table 1. The students characteristics $(n=370)$

\begin{tabular}{|c|c|c|c|}
\hline \multicolumn{2}{|l|}{ Characteristics } & $\mathbf{n}$ & $\%$ \\
\hline \multirow{2}{*}{$\begin{array}{l}\text { Satisfied with midwifery } \\
\text { education }\end{array}$} & Yes & 336 & 90.8 \\
\hline & No & 34 & 9.2 \\
\hline \multirow{2}{*}{$\begin{array}{l}\text { Wish to work as } \\
\text { midwives after } \\
\text { graduation }\end{array}$} & Yes & 327 & 88.4 \\
\hline & No & 43 & 11,6 \\
\hline \multirow[t]{2}{*}{ History of trauma } & No & 263 & 71,1 \\
\hline & Yes & 107 & 28,9 \\
\hline \multirow{2}{*}{$\begin{array}{l}\text { History of domestic } \\
\text { violence }\end{array}$} & No & 305 & 82,4 \\
\hline & Yes & 65 & 17,6 \\
\hline \multirow{2}{*}{$\begin{array}{l}\text { Witnessed incidents of } \\
\text { traumatic childbirth (for } \\
\text { example bleeding, low } \\
\text { apgar score and other } \\
\text { complications) }\end{array}$} & No & 131 & 35.4 \\
\hline & Yes & 239 & 64.6 \\
\hline \multirow{2}{*}{$\begin{array}{l}\text { Negative clinical } \\
\text { experience }\end{array}$} & Yes & 314 & 84,9 \\
\hline & No & 56 & 15,1 \\
\hline \multirow{3}{*}{$\begin{array}{l}\text { Negative experiences } \\
\text { that caused decrease } \\
\text { in the motivations of } \\
\text { midwifery students to } \\
\text { work as midwives }\end{array}$} & \begin{tabular}{|l|} 
Negative attitudes of \\
healthcare professional \\
towards pregnant women \\
during childbirth \\
\end{tabular} & 178 & 48,1 \\
\hline & $\begin{array}{l}\text { Negative attitudes of } \\
\text { healthcare personnel towards } \\
\text { students }\end{array}$ & 81 & 21,9 \\
\hline & $\begin{array}{l}\text { Reasons stemming from } \\
\text { childbirth room and its setting }\end{array}$ & 55 & 14,9 \\
\hline \multirow{5}{*}{$\begin{array}{l}\text { Reaction of the students } \\
\text { after the negative } \\
\text { experience }\end{array}$} & $\begin{array}{l}\text { Move away from clinical } \\
\text { setting }\end{array}$ & 188 & 50,8 \\
\hline & Fear & 184 & 49,7 \\
\hline & Cry & 104 & 28,1 \\
\hline & Anger & 88 & 23,8 \\
\hline & $\begin{array}{l}\text { Physiological responses such } \\
\text { as palpitations and nausea }\end{array}$ & 67 & 18,1 \\
\hline
\end{tabular}


Table 2. Emotional Labor Behavior Scale of Nurses mean scores of students $(n=370)$

\begin{tabular}{|l|l|l|}
\hline Scale & $\begin{array}{l}\text { Total } \\
\text { Mean } \pm \text { SD (Min-Max) }\end{array}$ & $\begin{array}{l}\text { Item } \\
\text { Mean } \pm \text { SD (Min-Max) }\end{array}$ \\
\hline The total scale & $96,52 \pm 11,92(52-120)$ & $4,02 \pm 0,49(2,17-5)$ \\
\hline $\begin{array}{l}\text { Superficial behavior } \\
\text { subscale }\end{array}$ & $23,81 \pm 3,33(9-30)$ & $3,96 \pm 0,55(1,50-5)$ \\
\hline $\begin{array}{l}\text { Deep behavior subscale } \\
51,95 \pm 7,33(25-65)\end{array}$ & $3,99 \pm 0,56(1,92-5)$ \\
\hline $\begin{array}{l}\text { Sincere behavior } \\
\text { subscale }\end{array}$ & $20,67 \pm 3,25(8-25)$ & $4,13 \pm 0,65(1,60-5)$ \\
\hline
\end{tabular}

Table 3. Comparison of the characteristics of students with Emotional Labor Behavior Scale of Nurses score $(n=370)$

\begin{tabular}{|c|c|c|c|c|c|}
\hline Characteristics & & $n$ & $\%$ & Mean \pm SD & $p$ \\
\hline \multirow{2}{*}{$\begin{array}{l}\text { Satisfied with midwifery } \\
\text { education }\end{array}$} & Yes & 336 & 90.8 & $96,98 \pm 11,58$ & \multirow{2}{*}{$\begin{array}{l}0,023^{*} \\
t=2,277\end{array}$} \\
\hline & No & 34 & 9.2 & $92,11 \pm 14,35$ & \\
\hline \multirow{2}{*}{$\begin{array}{l}\text { Wish to work as } \\
\text { midwives after } \\
\text { graduation }\end{array}$} & Yes & 327 & 88.4 & $96,72 \pm 11,70$ & \multirow{2}{*}{$\begin{array}{l}0,38^{*} \\
t=0,86\end{array}$} \\
\hline & No & 43 & 11,6 & $95,04 \pm 13,53$ & \\
\hline \multirow[t]{2}{*}{ History of trauma } & Yes & 107 & 28,9 & $97,40 \pm 12,80$ & \multirow{2}{*}{$\begin{array}{c}0,36^{*} \\
t=0,902\end{array}$} \\
\hline & No & 263 & 71,1 & $96,16 \pm 11,54$ & \\
\hline \multirow{2}{*}{$\begin{array}{l}\text { History of domestic } \\
\text { violence }\end{array}$} & Yes & 65 & 17,6 & $96,40 \pm 14,14$ & \multirow{2}{*}{$\begin{array}{c}0,92^{*} \\
t=0,089\end{array}$} \\
\hline & No & 305 & 82,4 & $96,55 \pm 11,42$ & \\
\hline \multirow{2}{*}{$\begin{array}{l}\text { Witnessed incidents of } \\
\text { traumatic childbirth }\end{array}$} & Yes & 239 & 64.6 & $96,94 \pm 11,25$ & \multirow{2}{*}{$\begin{array}{c}0,36^{*} \\
t=-0,903\end{array}$} \\
\hline & No & 131 & 35.4 & $95,75 \pm 13,11$ & \\
\hline
\end{tabular}

*Student $t$-test

Table 4. Comparison of the negative clinical experience of students with Emotional Labor Behavior Scale score $(n=370)$

\begin{tabular}{|c|c|c|c|c|c|c|}
\hline \multicolumn{3}{|l|}{ Characteristics } & $\mathrm{n}$ & $\%$ & Mean \pm SD & $p$ \\
\hline \multirow{2}{*}{\multicolumn{2}{|c|}{ Negative clinical experience }} & Yes & 314 & 84,9 & $96,61 \pm 11,78$ & \multirow{2}{*}{$\begin{array}{c}0,72^{*} \\
t=-0,352\end{array}$} \\
\hline & & No & 56 & 15,1 & $96,00 \pm 12,82$ & \\
\hline \multirow{6}{*}{$\begin{array}{l}\text { Negative experiences that caused } \\
\text { decrease in the motivations of midwifery } \\
\text { students to work as midwives }\end{array}$} & \multirow{2}{*}{$\begin{array}{l}\text { Negative attitudes of healthcare professional } \\
\text { towards pregnant women during childbirth }\end{array}$} & Yes & 178 & 48,1 & $96,36 \pm 12,38$ & \multirow{2}{*}{$\begin{array}{c}0,80^{*} \\
t=0,249\end{array}$} \\
\hline & & No & 192 & 51,9 & $96,67 \pm 11,51$ & \\
\hline & \multirow{2}{*}{$\begin{array}{l}\text { Negative attitudes of healthcare personnel } \\
\text { towards students }\end{array}$} & Yes & 81 & 21,9 & $96,23 \pm 11,33$ & \multirow{2}{*}{$\begin{array}{c}0,80^{*} \\
\mathrm{t}=0,246\end{array}$} \\
\hline & & No & 289 & 78,1 & $96,60 \pm 12,10$ & \\
\hline & \multirow{2}{*}{$\begin{array}{l}\text { Reasons stemming from childbirth room and } \\
\text { its setting }\end{array}$} & Yes & 55 & 14,9 & $97,98 \pm 10,48$ & \multirow{2}{*}{$\begin{array}{c}0,32^{*} \\
t=-0,981\end{array}$} \\
\hline & & No & 315 & 85,1 & $96,26 \pm 12,16$ & \\
\hline \multirow{10}{*}{$\begin{array}{l}\text { Reaction of the students after the negative } \\
\text { experience }\end{array}$} & \multirow[t]{2}{*}{ Move away from clinical setting } & Yes & 188 & 50,8 & $96,92 \pm 11,12$ & \multirow{2}{*}{$\begin{array}{c}0,52^{*} \\
t=-0,641\end{array}$} \\
\hline & & No & 182 & 49,2 & $96,12 \pm 12,72$ & \\
\hline & \multirow[t]{2}{*}{ Fear } & Yes & 184 & 49,7 & $96,96 \pm 11,84$ & \multirow{2}{*}{$\begin{array}{c}0,48^{*} \\
t=-0,694\end{array}$} \\
\hline & & No & 186 & 50,3 & $96,09 \pm 12,03$ & \\
\hline & \multirow[t]{2}{*}{ Cry } & Yes & 104 & 28,1 & $97,98 \pm 11,50$ & \multirow{2}{*}{$\begin{array}{c}0,14^{*} \\
t=-1,452\end{array}$} \\
\hline & & No & 266 & 71,9 & $95,96 \pm 12,06$ & \\
\hline & \multirow[t]{2}{*}{ Anger } & Yes & 88 & 23,8 & $96,29 \pm 12,78$ & \multirow{2}{*}{$\begin{array}{c}0,83^{*} \\
t=0,209\end{array}$} \\
\hline & & No & 282 & 76,2 & $96,60 \pm 11,66$ & \\
\hline & \multirow{2}{*}{$\begin{array}{l}\text { Physiological responses such as palpitations } \\
\text { and nausea }\end{array}$} & Yes & 67 & 18,1 & $96,66 \pm 13,27$ & \multirow{2}{*}{$\begin{array}{c}0,91^{*} \\
t=-0,105\end{array}$} \\
\hline & & No & 303 & 81,9 & $96,49 \pm 11,63$ & \\
\hline
\end{tabular}

*Student $t$-test

\section{DISCUSSION}

It is certainly remarkable that $85 \%$ of the students recruited for this study had negative clinical experiences that decreased their motivations to be midwives and what made these experiences were predominantly negative attitudes of healthcare personnel towards pregnant women and students themselves. ELBS total score mean of students was determined to be $96.52 \pm 11.92$ and ELBS scores of the students unsatisfied with midwifery education were significantly lower $(p<0,05)$. When the literature was reviewed, it was determined that $96 \%$ of midwifery students faced with serious ill-treatment and disrespectful behaviors during clinical practices similar to our research findings (14). Frequent physical and verbal abuse and even inhumane and extremely disrespectful attitudes in childbirth rooms were also witnessed as per the literature $(15,16)$. Došler et al. $(2014)$ states that $83 \%$ of midwifery students expose to mobbing in the clinical setting, an extremely high rate, while Malwela et al. (2016) specifies that professional midwives have negative behaviors towards students and act involuntarily when it comes to teach anything. In a qualitative study conducted with midwifery undergraduates, it is stated that when the women they offer 
care become disappointed or hurt, the students begin feeling what the women feel in a parallel and silent way and also feel themselves stressful, unsuccessful and inadequate (19). The most common reason why healthcare personnel in childbirth clinics act negatively towards women and midwifery students is their high levels of exhaustion $(20,21)$. In this context, it is of great importance for them to behave more humanely and professionally towards women and students. When this is achieved and settled, traumatization of both pregnant women and midwifery students can be avoided. According to Spiby et al. (2018) midwifery students were asked to give immediate feedback following their experiences not to be traumatized by possible negative experiences in the clinical setting and it was specified that when the students were supported later on, their learning outcomes came positive. And it is also considered really important that if mental health of the students are to be sustained, their supervisors must support and follow them closely after possible negative experiences in the clinical setting.

Midwifery as a profession requires sincere and empathy. As to the studies in the literature, when delivering women evaluate their own process as negative, their accompanying midwifery students may have more trouble and responsibility and their possibility of evaluating the birth as negative increases $(19,23)$. Cohen et al. (2017) states that mistaken attempts and birth complications affect the midwives negatively. On this basis, Pezaro et al. (2017) states that midwifery students experience serious psychological problems in their workplaces while Christensen (2018) specifies that mistaken medical practices, regardless of their seriousness or the harm inflicted on the patient, have an important mental and emotional cost and affect many students in a negative way. Hence, this study has similarly put forth that witnessing a complication decreases the motivation to be a midwife. Negative experiences of midwifery students in the clinical setting may cause them to take a quick dislike to their profession and decrease their sense of belonging. That is why these negative experiences may be minimized. In this study, mean score of emotional labor behavior of students who are not satisfied with their midwifery education and do not want to work as midwife after graduation were identified to be lower. Moreover, reported in the literature that tells us that when midwives are not prepared professionally and supported adequately during these practices, their self-confidence decrease and when they are not satisfied with their professional life and think of themselves as unable to give qualified care to delivering women and their families, they quit their jobs (2729). Therefore, midwifery education programs should be planned and written about the qualifications that students should be knowledgeable and equipped to understand the emotional needs of women. This perspective may increase the satisfaction of both service-taker and service-giver.

In this study, it was identified that midwifery students had the highest score for sincere behaviors amongst ELBS subscale scores. This finding is similar to the finding of another study conducted with midwife and nurses in Turkey $(30,31)$. It is expected that midwifery students exhibit more sincere behaviors towards women they give care in accordance with the nature of their profession. Midwifery by its definition requires so much emotional labor. The literature, which talks about the masculine and feminine aspects of emotional labor, focuses on attention, sympathy and harmony from female employees in the service sector; states that male employees are expected to behave towards intimidation, authoritarianism, and oppression (31,32).

It was also observed that as the fear of midwifery students' fear to vaginal birth management increased, their emotional labor behavior scores decrease. According to Dahlen and Caplice (2014), the reasons underlying midwives' fear to vaginal birth management can be listed as such: the fear of hurting the baby, perceived inability to manage the labour process, the fear of hurting the mother, the fear of harming oneself and some other individual fears. While Schroder et al. (2016) states that majority of midwives and obstetricians experiences a great deal of stress, Toohill et al. (2019) specifies that $8 \%$ of midwives have a great degree of fear to vaginal birth management. Additionally, Leinweber et al. (2017) reports that midwives may react with four times more fear while accompanying the childbirth where disrespectful or bad expressions are used. It is considered more beneficial to direct a midwife with a fear to vaginal birth management to a caesarean one since he/she can make a mistaken decision under the influence of that fear. The fear of midwives affect the childbirth process and the pregnant woman in a negative way (37). Any practice of student on a healthy/unhealthy individual is a great source of stress for both the student and the individual at stake. That the clinical practices of midwifery students happen in highly stressful places like childbirth room inevitably affect the emotional labor behaviors of students due to their dense feelings of fear.

In another study on fear it is stated that, by contrast with this study, the fear of midwives is not about childbirth but system and being tracked or examined (38). Likewise, Dahlen and Caplice (2014) specified that midwives had a dense fear of being tracked and criticized and they also included such factors as lack of support, pressures from any possible lawsuits, judgments, kind of oppressions, questioning and regulatory bodies. However, in this study, the fear of midwifery students is founded to be related to hurting the mother and baby rather than being sued. Moreover, it is remarkable that the problem here is not to make no intervention, which is quite against the nature of the birth but to focus negatively on necessary invasive attempts (e.g: implementations about episiotomy). It is also understood that the midwifery students have not developed any kind of consciousness for certain cases that will create so many concerns and thus felt no responsibility (no fear for being sued etc.).

\section{CONCLUSION}

That $85 \%$ of students recruited for the research have had at least one negative clinical experience leading decrease in their motivations to be a midwife is a quite high rate. One of the underlying reasons that reduce their motivations to work 
as midwife in clinical settings is "healthcare professional's negative behavior towards pregnant women and students during the labour", which can be avoided. It is considered that certain interventions must be made to decrease such negative behaviors of healthcare professional and also students must be supported by their educators. The students must be supported professionally when they have to cope with such experiences. Thus, students will be able to give more emotional labor and more motivated and empathic care. It is determined that clinical negative experiences do not affect students' emotional labor behavior. The concept of emotional labor has gained a value increasing with each passing day when its individual and organizational effects are considered. In addition, further work should be done to identify other factors affecting emotional labor behaviors between midwives and other healthcare professionals.

\section{Funding Sources}

The expenses of the study were covered by the researchers.

\section{Conflict of Interest}

The authors declare that they have no conflict of interest.

\section{REFERENCES}

[1] Eren D, Demirel N. The effect of emotional labor factor on service quality: an investigation on four-five star hotels in Nevsehir. Igd Univ Jour Soc Sci 2018; 310-334. (Turkish)

[2] Kaya U, Serceoglu N. Work alienation among emotion workers: A research in service industry. Labour and Society 2013; 13(1):311-346. (Turkish)

[3] Onay $M$. The effect of emotional intelligence and emotional labor on task performance and contextual performance, Ege Academic Review 2011; 11(4):587-600. (Turkish)

[4] Gungor M. The phenomenon of emotional labour: Process and outcomes. Kamu-Is Hukuku ve Iktisat Dergisi 2009; 11(1):167184. (Turkish)

[5] Gulova AA, Palamutcuoglu BT, Palamutcuoglu AT. The role of supervisor support in relations between emotional labor and job involvement: A research on university student affairs personnel. Dokuz Eylül Üniversitesi İktisadi ve İdari Bilimler Fakültesi Dergisi 2013; 28(2):41-74. (Turkish)

[6] Akoglan Kozak M, Guclu Nergis H. An Investigation into the use of emotional labor factors in the employment process in tourism enterprises. Anadolu University Journal of Social Sciences 2008; 8(2):39-56. (Turkish)

[7] Diefendorff JM, Croyle MH, Gosserand RH. The dimensionality and antecedents of emotional labor strategies. Journal of Vocational Behavior 2005; 66(2):339-357.

[8] Hodnett ED, Gates S, Hofmeyr G, Sakala C. Continuous support for women during childbirth. Cochrane Database Syst Rev 2013; $15: 7$.

[9] Adeniji OG, Akanni AA, Ekundayo OO. Gender difference in emotional labour among nurses in Osun state, Nigeria. Gender \& Behaviour 2015; 13(2):6789-6794.
[10] Bohren MA, Hofmeyr G, Sakala C, Fukuzawa RK, Cuthbert A. Continuous support for women during childbirth. Cochrane Database Syst Rev 2017; 6:7.

[11] Ozgun A. The effect of emotional labor on work stress: An application in education sector. Dokuz Eylül University. Graduate School of Social Science, Department of Business Administration, Management and Organization Program, Master's Thesis. 2015. (Turkish)

[12] Degirmenci Oz S, Baykal U. Developing in the scale of emotional labor behavior for nurses. International Refereed Journal of Nursing Researches 2018; 12:119-139. (Turkish)

[13] Yıldırım A, Simsek H. Qualitative Research Methods. Updated Improved 5th Edition. Ankara: Seckin Publishing: 2008. (Turkish)

[14] Moyer CA, Rominski S, Nakua EK, Dzomeku VM, AgyeiBaffour P, Lori JR. Exposure to disrespectful patient care during training: Data from midwifery students at 15 midwifery schools in Ghana. Midwifery 2016; 41:39-44.

[15] Bradley S, McCourt C, Rayment J, Parmar D. Disrespectful intrapartum care during facility-based delivery in sub-Saharan Africa: A qualitative systematic review and thematic synthesis of women's perceptions and experiences. Soc Sci Med 2016; 169:157-170.

[16] Burrowes S, Holcombe SJ, Jara D, Carter D, Smith K. Midwives' and patients' perspectives on disrespect and abuse during labor and delivery care in Ethiopia: a qualitative study. BMC Pregnancy Childbirth 2017; 22:17.

[17] Došler AJ, Skubic M, Mivšek AP. Perception of mobbing during the study: results of a national quantitative research among Slovenian midwifery students. Coll Antropol 2014; 38(3):10091015.

[18] Malwela T, Maputle SM, Lebese RT. Factors affecting integration of midwifery nursing science theory with clinical practice in Vhembe District, Limpopo Province as perceived by professional midwives. Afr J Prim Health Care Fam Med 2016; 24:8(2), e1-6.

[19] Davies S, Coldridge L. "No Man's Land": An exploration of the traumatic experiences of student midwives in practice. Midwifery 2015; 31(9):858-864.

[20] Agapinar S, Sahin HG. The effects of the levels of burnout midwives working in agrı on the job satisfaction and empathic tendencies of them. TAF Prev Med Bull 2014; 13(2):141-150. (Turkish)

[21] Karaca Sivrikaya S, Erisen M. Examination of burnout and workrelated tension levels of health workers. Journal of Anatolia Nursing and Health Sciences 2019; 22(2):121-129. (Turkish)

[22] Spiby H, Sheen K, Collinge S, Maxwell C, Pollard K, Slade P. Preparing midwifery students for traumatic workplace events: Findings from the POPPY (programme for the prevention of posttraumatic stress disorder in midwifery) feasibility study. Nurse Educ Today 2018; 71:226-232.

[23] Rice $\mathrm{H}$, Warland J. Bearing witness: midwives experiences of witnessing traumatic birth. Midwifery 2013; 29;(9):1056-1063.

[24] Cohen R, Leykin D, Golan-Hadari D, Lahad, M. Exposure to traumatic events at work, posttraumatic symptoms and professional quality of life among midwives. Midwifery 2017; 50:1-8.

[25] Pezaro S, Clyne W, Fulton EA. A systematic mixed-methods review of interventions, outcomes and experiences for midwives and student midwives in work-related psychological distress. Midwifery 2017; 50:163-173. 
[26] Christensen L. Are clinical instructors preventing or provoking adverse events involving students: A contemporary issue. Nurse Educ Today 2018; 70:121-123.

[27] Catling C, Reid F, Hunter B. Australian midwives' experiences of their workplace culture. Women Birth 2016; 30(2):137-145.

[28] Pugh J, Twigg D, Martin T, Rai, T. Western Australia facing critical losses in its midwifery workforce: a survey of midwives' intentions. Midwifery 2013; 29(5):497-505.

[29] Royal College of Midwives (RCM). Why midwives leave revisited. 2016. Available from: URL: https://www.rcm. org.uk/sites/default/files/Why\%20Midwives\%20Leave\%20 Revisted\%20-\%200ctober\%202016.pdf

[30] Sonkaya MC. Examination of emotional labor behavior in nurses: A university hospital example. Karabuk University. Health Science Enstitute, Master's Thesis. 2018. (Turkish)

[31] Atasoy I, Turan Z. Investigation of the relationship between midwives' and nurses' emotional labor and life satisfaction. Lokman Hekim Journal of History of Medicine and Folk Medicine 2019; 9(3): 357-366. (Turkish)

[32] Ozkaplan N. Duygusal emek ve kadın işi/erkek işi. Labour and Society 2009; 2:15-24. (Turkish)
[33] Dahlen HG. Caplice S. What do midwives fear? Women and Birth 2014; 27(4):266-270.

[34] Schroder K, Jorgensen J, Lamont R, Hvidt N. Blame and guilt - a mixed methods study of obstetricians' and midwives' experiences and existential consider-ations after involvement in traumatic childbirth. Acta Obstet Gynecol Scand 2016; 95:735-745.

[35] Toohill J. Fenwick J. Sidebotham M, Gamble J, Creedy DK. Trauma and fear in Australian midwives. Women Birth 2019; 32(1):64-71.

[36] Leinweber J, Creedy D, Rowe H, Gamble J. Responses to birth trauma and prevalence of posttraumatic stress among Australian midwives. Women Birth 2017; 30(1):40-45.

[37] Regan M. Liaschenko J. In the mind of the be holder: hypothesized effect of intrapartum nurse's cognitive frames of childbirth caesarean section rates. Qual Health Res 2007; 17(5):612-634.

[38] Copeland F. Dahlen HG, Homer, CS. Conflicting contexts: midwives' interpretation of childbirth through photo elicitation. Women And Birth 2014; 27(2):126-131.

How to cite this article: Bayri Bingol F, Demirgoz Bal M, Aygun M, Bilgic E. Effect of Midwifery Students' Negative Clinical Experiences on Their Emotional Labor Behaviors. Clin Exp Health Sci 2020; 10: 382-388. DOI: 10.33808/clinexphealthsci.679565 